\title{
Arabic-speakers Learning Finnish Vowels: Short- term Phonetic Training Supports Second Language Vowel Production
}

\author{
Satu Savo \\ Phonetics and Learning, Age \& Bilingualism Laboratory, Department of Future Technologies, University of Turku, \\ Finland \\ Maija S. Peltola \\ Phonetics and Learning, Age \& Bilingualism Laboratory, Department of Future Technologies, University of Turku, \\ Finland
}

\begin{abstract}
Considering all the many challenges of forced migration to the immigrants themselves, learning the local language is of extreme importance when attempting to integrate into a new society. Earlier research shows that the mother tongue phonology disturbs the perception of those redundant contrasts that are crucial to the target language, which then affects the production of the second language. The main purpose of this study was to see whether Arabic speakers learn to produce universally difficult non-native vowel sounds with only a short and simple articulatory training protocol. Thirteen Arabic speaking asylum seekers were test ed and trained with natural stimuli produced by four speakers. The vowels $/ y /$ and $/ \varnothing /$ were embedded in pseudowords /ty:ti/ and /tø:ti/. The first three formants of both pre- and post-test productions were analyzed, and the results of both acoustic and statistical analyses showed that there was a significant change in the production of both vowels. This implies that even a short-term phonetic training improves the production of the target language, which is worth noting as an enabler of the language learning process that immigrants undergo during their journey towards cultural integration.
\end{abstract}

Index Terms - immigrants, vowel production training, second language learning

\section{INTRODUCTION}

Oral communication between humans relies on speech perception and production. Speech perception starts to develop already during pregnancy (Kuhl, 2000) and approximately six months after birth the infant develops a language-specific perception for vowels (Kuhl, 2004). The perceptual learning process is based on detecting patterns and exploiting statistical properties, which perceptually changes the infant's language capacity (Kuhl, 2000). The memory traces of native speech sounds (Näätänen et al., 1997) function as patterns that help to establish phonological categories of native speech sounds within the first year of life (Kuhl, Williams, Lacerda, Stevens \& Lindblom, 1992). As the native speech sound categories have been formed in the process of acquisition, non-native sounds become redundant. The perception process enables the learning of speech production, starting with the infant developing production patterns with the help of native language acoustic model and articulatory gestures: the auditory feedback mechanism helps to evaluate whether the produced speech is consistent with the acoustic-auditory intention (Perkell, 1997).

Traditional second language acquisition (SLA) theories support the idea that one must remodel the native language sound system in order to learn the sounds of a foreign language. According to Lado (1957), phonemes are transferred from the native language system into the second language system, emphasis being on the phonemic and non-phonemic differences. Weinreich's theory classifies the learning problems according to the level of difficulty, underdifferentiation being the most challenging learning situation (Weinreich, 1968). Following the traditional theories to some extent, the more recent SLA model, the Speech Learning Model (SLM), divides sound differentiation into three types: identical, new and similar. On the level of difficulty, the identical phone is the most undemanding situation for a second language learner. A completely new sound that does not have any similar qualities to other sounds in the native system takes more time and effort to learn, yet it will be correctly pronounced over time. Reflecting on both perception and production the highest learning difficulty arises when the foreign sound is similar to a native sound and is therefore too easily perceived and pronounced incorrectly (Flege, 1987). The Perceptional Assimilation Model (PAM) divides the relations of first and second languages into four assimilation patterns: (1) two second language (L2) categories assimilate into two native language (L1) categories, which is the same situation as the identical sounds of SLM. (2) L2 phones differ from L1 categories too notably to be assimilated, like the new sound in SLM. The remaining two types of assimilation describe the same problem as the similar sound in SLM: (3) the two L2 phonemes assimilate into one L1 category equally well or equally poorly or (4) two L2 phonemes assimilate into one L1 category unequally (Best \& 
Strange, 1992). The most problematic assimilation pattern is the one in which two L2 categories assimilate into one L1 category equally well or equally poorly. The second most difficult assimilation pattern is the one listed above as the last one - two L2 phonemes assimilate into one L1 category unequally. L2 phones differing from L1 categories too substantially to be assimilated is considered the third most problematic assimilation pattern, and the most undemanding pattern is the first one listed above - two L2 categories assimilating into two L1 categories.

Despite the effect of the native language on second language learning, previous research has shown that training helps different types of language learners to defeat the occurring learning difficulties. Child learners have improved their production patterns when tested with a listen-and-repeat training (Taimi, Alku, Jähi \& Peltola, M.S., 2014), as have senior learners, too (Jähi, Alku \& Peltola, M. S., 2015). Adult learners benefit from training whether they are learning a second language in a classroom setting (Peltola, M. S., Lintunen \& Tamminen, 2014) or as immigrants (Flege, Bohn, \& Jang, 1997). MMN studies have also revealed that immigrants are able to develop cortical memory representations for the foreign phoneme system and categorize language-specific phonemes preattentively (Winkler et al., 1999). Earlier studies have shown that phonetic listen-and-repeat production training not only improves non-native language perception and makes significant changes in the MMN responses (Tamminen \& Peltola, 2015, Tamminen, Peltola, M. S., Kujala \& Näätänen, 2015), but also improves non-native vowel production (Taimi, Alku, Jähi \& Peltola, M.S., 2014). As for the different levels of training, one of the most significant of early studies in second language training showed that phonetic training improves perception on the same type of stimuli but does not generalize to natural stimuli, for example (Strange \& Dittman, 1984).

This study examines the Finnish vowel production training of Arabic speaking asylum seekers residing in Finland. There are only three short vowels and their long counterparts (/i/, /u/ and /a/) in the Arabic system (IPA, 1999), while there are eight vowels $(/ \mathrm{i} /, / \mathrm{e} /, / \mathfrak{e} /, / \mathrm{y} /, / \varnothing /, / \mathrm{u} /, / \mathrm{o} /$ and $/ \mathrm{a} /)$ in the Finnish sound system. Considering the Arabic and Finnish sound systems, especially the universally difficult Finnish vowels /y/ and / $\varnothing /$ are difficult for Arabic speakers to identify and pronounce. In this study the focus is on the production of the above-mentioned universally difficult vowels $/ y /$ and $/ \varnothing /$. For Arabic speakers the Finnish /y/ is closest to their native /i/ and differs in pronunciation by the lip posture: lips are vastly spread in /i/ but heavily rounded when pronouncing /y/. The Finnish / $\varnothing /$ is rather in the middle of /i/ and /a/ in Arabic - it is a complicated sound, since learners need to find a tongue position in the middle of their two familiar phonemes /i/ and /a/ that are at the very opposite ends in height. In addition to that, lips need to be rounded, which is not a familiar characteristic for Arabic front vowels. Considering the foregoing second language learning theories, these two Finnish vowels are difficult to produce and therefore make logical targets for a listen-and-repeat training.

Over the recent years, forced migration has been a major subject of discussion especially in Europe, often referred to as the "migration crisis." Due to the devastating events (coups, war, terrorism) in their home countries, many habitants of the Middle East have left and sought for asylum in Europe. Looking at this issue from a linguistic point of view, new challenges naturally arise as a growing amount of people from different language and cultural backgrounds start a new life in an alien culture. More second language teachers will be needed, and additional education needs to be provided to teachers who are in charge of teaching the target language. Arabic is the native language to a large part of asylum seekers in Finland (Finnish Immigration Service, 2018), which is why it is important to study the relationship between Arabic and Finnish more closely. Considering this relationship, especially some of the Finnish vowels are easily mispronounced by Arabic speakers if not practiced with the help of a native speaker. Therefore, the aim of this study is to confirm the need of vowel pronunciation training from the very start of second language learning by proving that even short-term phonetic training improves second language vowel production.

\section{Methodology}

\section{A. Participants}

Thirteen 17-54-year-old (mean 32.4 years) Arabic speaking male subjects participated in the study. The participants had resided in Finland from one to six months (length of residence, LOR, 4.1 months in average). They had participated in Finnish lessons for up to three months (1.9 months in average), but were not able to communicate in Finnish at the time of the testing. Most participants had learned English at some point in their lives, varying from a few months to over 20 years of exposure. None of the subjects had learned languages in which the sounds /y/ or / $\varnothing /$ are included in the vowel system. All participants reported to have a normal hearing.

\section{B. Design of the Study and Data Collection}

All subjects were tested and trained according to the same procedure that lasted for approximately 30 minutes. The procedure was conducted in three different reception centers in Turku using LAB-lab portable laboratory containing Sanako Study Student 7.20 (7.20.030508.00) software on a laptop (Dell Latitude E7240) and Beyerdynamic MMX 300 headset. The aim at the reception center was to find a quiet place without any disruption, yet it was not always possible. However, the high-quality headset blocked the possible external noises and the data was obtained successfully.

After collecting background information (age, LOR, education, foreign language skills) and getting a written consent from each participant, the subjects were asked to listen and repeat pseudo-words /ty:ti/ and /tø:ti/ (each word 12 times) for the baseline (pre-test) measurement. The inter stimulus interval (ISI) was 2.5 seconds, during which the subjects 
were asked to imitate the word they heard. This measurement was followed by the training block that included the baseline measurement block repeated four times, resulting in 48 stimuli per pseudo word. After the first training session, the participants were asked to have a 5-10-minute break. The same training block was repeated after the break. The final (post-test) recording was identical to the baseline measurement. The participants repeated altogether 240 stimuli out of which 48 were recorded and then analyzed.

\section{Stimuli}

Four speakers (two females and two males) were selected to produce natural stimuli for this study. The same Beyerdynamic headset was used both when recording the stimuli and when testing and training participants. We recorded the speech of these four speakers on Praat software: both of the pseudo words /ty:ti/ and /tø:ti/ ten times. Three words out of ten were chosen to be used as stimuli according to their proportion of vowel duration to word duration in order to avoid any problems that might appear in case the target vowel is too long or too short compared to other stimuli. In addition to being universally difficult, the target vowels $/ y /$ and $/ \varnothing /$ were chosen because these phonemes are unfamiliar and, according to SLA theories, difficult to pronounce for Arabic speakers. The target sounds were long because longer duration gives more time for the subject to process what he heard and repeat it after. Of all consonants, the alveolar plosive / $t$ / causes least changes to neighboring sounds, which is why it was chosen to be a suitable environment for the target vowel. /i/ is a suitable vowel in the end of the pseudo word because the subjects are familiar with it in their native language and, therefore, they will be less likely to pay attention to the final vowel. Thus, the participants can focus on pronouncing the target vowels.

\section{Data Analysis}

The production data of all participants was acoustically analyzed using Praat software (version 5.3.01). Altogether 624 productions ( 24 words x 13 participants x 2 measurements) were analyzed by obtaining the following measures in each production: word duration, vowel duration, F0, F1 and F2 values of the target vowel. In addition to acoustic analyses, statistical analyses were conducted, and the data was subjected to a Repeated Measures Analysis of Variance (ANOVA).

\section{RESULTS}

The statistical analysis was carried out using a Word (2) x Session (2) x Measure (2) repeated measures analysis of variance (ANOVA). The main effect of Word $(\mathrm{f}(1,16)=8.677, \mathrm{p}=0,009)$ describes the existing difference between vowels $(f(1,16)=246,819, p<0,001)$. We found a main effect of Session $(f(1,16)=12.248, p=0,003)$ which indicates that the production changed as a function of training. In addition, there was a Session $\mathrm{x}$ Word interaction $(\mathrm{f}(1,16)=12.951$, $\mathrm{p}=0,002$ ) showing that the training had an impact on the target vowels. The Session $\mathrm{x}$ Measure interaction $(\mathrm{f}(1,16)=9.397, \mathrm{p}=0,007)$ confirms that the formants change differently.

As for the target vowel $/ y /$, the inspection of the acoustic difference suggests that the largest mean formant change between pretest and post-test is found in $F_{2}$ values. The mean $F_{2}$ value in pretest was $1416 \mathrm{~Hz}$ but it increased after training by $187 \mathrm{~Hz}$. The greatest dispersion lies in the pretest $\mathrm{F}_{2}$ values (minimum $938 \mathrm{~Hz}-$ maximum $1799 \mathrm{~Hz}$, range $861 \mathrm{~Hz}$ and Standard Deviation (STD) $331 \mathrm{~Hz}$ ): this indicates that there were vast differences between the participants' pretest $\mathrm{F}_{2}$ values. The mean $\mathrm{F}_{1}$ values of /y/ increased by $11 \mathrm{~Hz}$ after training. There was a typical pattern occurring in many productions: the subjects tried to produce the target vowel by combining the familiar vowels /i/ and /u/, which resulted in the diphthong/iu/. While many participants clearly struggled in the pretest, some already appeared to have started from a rather decent level. Furthermore, in some cases the productions varied immensely within-subject; a few subjects had the tendency to pronounce approximately every other word as a different word (eg. "tuuti" - "tööti" "tyyti" - "tuuti", etc.) which would explain why within a single participant's test block acoustic measurements some words seem to have very successful formant values and some are remarkably far from the target values.

The most extensive mean difference among the formant values for $/ \varnothing /$ was found between pretest and post-test $F_{2}$ values $(63 \mathrm{~Hz})$. The most substantial dispersion in the measured values of $/ \varnothing /$ was found in the pretest $F_{2}$ values (minimum $938 \mathrm{~Hz}$ - maximum $1778 \mathrm{~Hz}$, range $840 \mathrm{~Hz}$ and STD $254 \mathrm{~Hz}$ ). Despite / $/$ / being a mid-height and falling in between the Arabic /a/ and /i/ categories, the participants succeeded to raise the mean $\mathrm{F}_{1}$ values by $21 \mathrm{~Hz}$. Moreover, the $F_{1}$ minimum value between pretest and post-test increased by $71 \mathrm{~Hz}$. The subjects' $F_{1}$ values of $/ \varnothing /$ were already fairly native-like in the pretest but the mean $\mathrm{F}_{2}$ values were approximately $200 \mathrm{~Hz}$ short from the target. This indicates that their tongue is too retracted possibly due to excess lip rounding, which will not necessarily be corrected by training. Nevertheless, some subjects' individual mean $\mathrm{F}_{2}$ values were over $1700 \mathrm{~Hz}$ already in the pretest. Remarkably, the maximum $\mathrm{F}_{2}$ values also decreased after training. Similarly to the way the subjects often pronounced /ty:ti/ as /tiuti/, /tø:ti/ also had a regular mispronunciation pattern /tojoti/. The palatal approximant/j/ functions as an aid for reaching the target sound. 
TABLE 1

\begin{tabular}{lllllllll}
\hline$/ y /$ & Mean Pre & Mean Post & Min Pre & Min Post & Max Pre & Max Post & Std. Deviation Pre & Std. Deviation Post \\
$\mathrm{F}_{1}$ & 368 & 379 & 275 & 324 & 435 & 433 & 42.89 & 29.16 \\
$\mathrm{~F}_{2}$ & 1416 & 1604 & 938 & 1003 & 1799 & 1723 & 344.79 & 271.59 \\
$/ \varnothing /$ & Mean Pre & Mean Post & Min Pre & Min Post & Max Pre & Max Post & Std. Deviation Pre & Std. Deviation Post \\
$\mathrm{F}_{1}$ & 481 & 501 & 356 & 426 & 543 & 542 & 52.24 & 34.34 \\
$\mathrm{~F}_{2}$ & 1464 & 1526 & 938 & 1103 & 1778 & 1720 & 264.58 & 220.61 \\
\hline
\end{tabular}

\section{DISCUSSION}

The main purpose of the present study was to see whether Arabic speakers learn to produce universally difficult nonnative vowel sounds with only a short and simple articulatory training protocol. The hypothesis was that the conducted short-term phonetic training will result in improvement of production performance on both target vowels, and the results support this hypothesis. /y/ and / $\varnothing /$ are both secondary cardinal vowels and less commonly found in the vowel systems of the world's languages (Ladefoged \& Maddieson, 1996), and from the perspective of the native language these sounds are extremely difficult to produce. Within the framework of SLM (Flege, 1987), it can be argued that /y/ is a Similar sound to Arabic speakers, because the results suggest that the participants attempt to accomplish the correct pronunciation through the native /u/, yet the $\mathrm{F}_{2}$ values do not still reach a fully native-like level. The assimilation pattern of Category Goodness Difference (Best \& Strange, 1992) is suitable to describe the relationship between /y/ and /u/: they both assimilate into the native category / $\mathrm{u} /$, only /y/ is a poorer representative of the category. Another option is that the sound is learned as New and is Non-Assimilable, but the first option ought to be more plausible. The Finnish vowel $/ \varnothing /$ is placed between the native Arabic vowel phoneme categories /i/ and /a/, but it seems to be positioned too far to be assimilated into either of those native categories. Especially lip-rounding seems to affect pronunciation rather deeply: interestingly, according to the acoustic measurements, some subjects seek for the correct pronunciation through /o/ (which is also not a native sound to Arabic speakers). From the perspective of Arabic as the native language, it is reasonable to consider / $\varnothing /$ a New (SLM, Flege, 1987) and a Non-Assimilable sound (PAM, Best \& Strange, 1992).

The study was operated using a listen-and-repeat phonetic training protocol featuring two non-native vowels embedded in pseudo-words, which is the type of phonetic training that has been productively utilized in previous studies (Jähi, Alku \& Peltola, M. S., 2015, Peltola, K. U., Tamminen, Alku \& Peltola M.S., 2015, Taimi, Alku, Jähi \& Peltola, M.S., 2014). While the afore-mentioned studies were based on a two-day production training, the current study investigated the possible effects of a shorter training period. Also, instead of a native-non-native contrast the subjects learn to improve their production of two non-native target vowels. Interestingly, another short-term training study tested the ability of Finnish and American English speakers to produce a non-native vowel contrast (/ty:ti/ - /tu:ti/), yet according to their results both groups failed to improve their productions and continued to produce the pseudo-words according to the mother tongue model (Peltola, K. U., Rautaoja, Alku \& Peltola, M. S., 2017). How is it possible that the Arabic speakers improved their production even though the target vowels are universally difficult and the training period was relatively short? What exactly makes this training so efficient? The difference between the compositions of the above-mentioned training studies (Jähi, Alku \& Peltola, M. S., 2015, Peltola, K.U., Rautaoja, Alku \& Peltola, M. S., 2017, Peltola K. U., Tamminen, Alku \& Peltola M. S., 2015, Taimi, Alku, Jähi \& Peltola, M.S., 2014) and the current study is immense - more training and only one target sound - hence it could have been possible that the Arabic speaking participants would have needed more training in order to improve the production of these two non-native target vowels. The stimuli are also different: while previous studies have been conducted utilizing semi-synthetic stimuli, the stimuli in the current study were naturally produced by four different speakers. Considering the short-period training study on Finnish and American English speakers (Peltola, K.U., Rautaoja, Alku \& Peltola, M. S., 2017), there are a few differences between that and the current study that may explain the contradictory results: firstly, the study conducted by Peltola, K. U., Rautaoja, Alku \& Peltola, M. S. (2017) entailed two different language groups, and secondly, the current study focused on two non-native target vowels whereas Peltola, K. U., Rautaoja, Alku \& Peltola, M. S. (2017) designed their study for a non-native vowel contrast (/y/ not being a target vowel for the Finnish speakers). Thirdly, the native Arabic vowel system is less complex than the American English one, which may facilitate the nonnative target vowel production. However, the question of whether a more complex L1 vowel inventory supports second language acquisition and production because of more successful assimilation or hinders it due to the difficulty of learning new categories, remains fully unanswered as the research results remain contradictory. A vowel identification study conducted by Iverson and Evans (2007) contradicts with the results of the current study - their results suggest that a larger vowel inventory facilitates learning instead of hindering it. This contradiction increases the significance of the current result and it must be further investigated whether it is particularly the native language Arabic and its vowel system that generated such rapid improvement in production.

\section{CONCLUSION}


The most remarkable finding of this study is that the improvement in production happens so fast with such a short training. The result is promising from the perspective of teaching Finnish as a second language to asylum seekers and immigrants, and it can be assumed that further training will continue to strengthen the improvement of production. The ability to speak the language of the society one is integrating into is crucial and it stands to reason that being understood by native speakers improves one's confidence, which creates better prospects for one's future in a new society. Therefore, pronunciation training should gain more status in the curriculum of second language learning.

\section{ACKNOWLEDGEMENTS}

The authors wish to thank all the subjects for participating in this study and all reception center coordinators who arranged meetings with the participants. We also warmly thank Sanako Corp. for sponsoring the LAB-laboratory. Additionally, we wish to express our gratitude to Antti Saloranta, MA, for valuable technical support in the project. This work was supported in part by a grant for the first author from Turku Finnish University Society (Valto Takala fund).

\section{REFERENCES}

[1] Best, C. T. \& Strange, W. (1992). Effects of phonological and phonetic factors on cross-language perception of approximants. Journal of Phonetics, 20(3), 305-330. URL: http://www.haskins.yale.edu/sr/SR109/SR109_07.pdf.

[2] Finnish Immigration Service. (2018). Asylum seekers statistics (1.11.2017). URL: http://migri.fi/documents/5202425/6161882/65764_tp-hakijat_2016.pdf (accessed 1/6/2018).

[3] Flege, J. E. (1987). The production of new and similar phones in a foreign language: evidence for the effect of equivalence classification. Journal of Phonetics, 15, 47-65. URL: http://www.jimflege.com/files/Flege_new_similar_JP_1987.pdf.

[4] Flege, J. E., Bohn, O.-S. \& Jang, S. (1997). Effects of experience on non-native speakers' production and perception of English vowels. Journal of Phonetics, 25(4), 437-470. doi: 10.1006/jpho.1997.0052.

[5] International Phonetic Association. (1999). Handbook of the International Phonetic Association: A Guide to the Use of the International Phonetic Alphabet. Cambridge: Cambridge University Press.

[6] Iverson, P., Evans, B. G. (2007). Learning English vowels with different first-language vowel systems II: Perception of formant targets, formant movement, and duration. Journal of the Acoustical Society of America, 122(5):2842-2854. doi: $10.1121 / 1.2783198$.

[7] Jähi, K., Alku P. \& Peltola M. S. (2015). Does interest in language learning affect the non-native phoneme production in elderly learners? In The Scottish Consortium for ICPhS 2015 (eds.), Proceedings of the 18th International Congress of Phonetic Sciences. Glasgow, UK: the University of Glasgow. ISBN 978-0-85261-941-4. Paper number 234.

[8] Kuhl, P. K. (2000). A new view of language acquisition. Proceedings of the National Academy of Sciences, 97(22):1185011857. doi: 10.1073/pnas.97.22.11850.

[9] Kuhl, P. K. (2004). Early language acquisition: cracking the speech code. Nature Reviews Neuroscience, 5:831-843. doi: $10.1038 / \mathrm{nrn} 1533$.

[10] Kuhl, P. K., Williams K. A., Lacerda F., Stevens K. N. \& Lindblom B. (1992). Linguistic experience alters phonetic perception in infants by 6 months of age. Science, 255, 606-608. doi: 10.1126/science.1736364.

[11] Ladefoged, P. \& Maddieson, I. (1996). The sounds of the world's languages. Oxford: Blackwell.

[12] Lado, R. (1957). Linguistics across cultures. Michigan: University of Michigan Press.

[13] Näätänen, R., Lehtokoski, A., Lennes, M., Cheour, M., Huotilainen, M., Iivonen, A., Vainio, M., Alku, P., Ilmoniemi, R.J., Luuk, A., Allik, J., Sinkkonen, J. \& Alho, K. (1997). Language-specific phoneme representations revealed by electric and magnetic brain responses. Nature, 385:432-434. doi: 10.1038/385432a0.

[14] Peltola, K. U., Rautaoja, T., Alku, P. \& Peltola, M. S. (2017). Adult learners and a one-day production training - Small changes but the native language sound system prevails. Journal of Language Teaching and Research, 8, 1-7. doi 10.17507/j1tr.0801.01.

[15] Peltola, K.U., Tamminen H., Alku P. \& Peltola M.S., (2015). Non-native production training with an acoustic model and orthographic or transcription cues. In The Scottish Consortium for ICPhS 2015 (Ed.), Proceedings of the 18th International Congress of Phonetic Sciences. Glasgow, UK: the University of Glasgow. ISBN 978-0-85261-941-4. Paper number 0236.

[16] Peltola, M. S., Lintunen P. \& Tamminen H. (2014). Advanced English learners benefit from explicit pronunciation teaching: an experiment with vowel duration and quality. In: P. Lintunen, M.S. Peltola \& M.-L. Varila (Eds.) AFinLA-e Soveltavan kielitieteen tutkimuksia, 6, 86-98. URL: https://journal.fi/afinla/article/view/46282.

[17] Perkell, J., Matthies, M., Lane, H., Guenther, F., Wilhelms-Tricarico, R., Wozniak, J., \& Guiod, P. (1997). Speech motor control: acoustic goals, saturation effects, auditory feedback and internal models. Speech Communication, 22:227-250. doi: 10.1016/S0167-6393(97)00026-5.

[18] Strange, W. \& Dittmann, S. (1984). Effects of discrimination training on the perception of /r-1/ by Japanese adults learning English. Perception \& Psychophysics, 36(2):131-145. doi: 10.3758/BF03202673.

[19] Taimi, L., Jähi, K., Alku, P. \& Peltola M. S. (2014b). Children Learning a Non-native Vowel - The Effect of a Two-day Production Training. Journal of Language Teaching and Research, 5, 1229-1235. doi: 10.4304/jltr.5.6.1229-1235.

[20] Tamminen, H. \& Peltola M.S. (2015). Non-native memory traces can be further strengthened by short term phonetic training. In The Scottish Consortium for ICPhS 2015 (Ed.), Proceedings of the 18th International Congress of Phonetic Sciences. Glasgow, UK: the University of Glasgow. ISBN 978-0-85261-941-4. Paper number 0285.

[21] Tamminen, H., Peltola, M. S., Kujala, T. \& Näätänen, R. (2015). Phonetic training and non-native speech perception - New memory traces evolve in just three days as indexed by the mismatch negativity (MMN) and behavioural measures. International Journal of Psychophysiology, 97(2015), 23-29. doi: 10.1016/j.ijpsycho.2015.04.020.

[22] Weinreich, U. (1953/1968). Languages in contact. Mouton, The Hague. 
[23] Winkler, I., Kujala, T., Tiitinen, H., Sivonen, P., Alku, P., Lehtokoski, A., Czigler, I., Csépe, V., Ilmoniemi, R.J., Näätänen, R. (1999). Brain responses reveal the learning of foreign language phonemes. Psychophysiology, 36, 638-642. doi: 10.1111/14698986.3650638 .

Satu Savo, MA, is a graduate from Phonetics and Learning, Age and Bilingualism Laboratory (LAB-lab), Department of Future Technologies, University of Turku. She is interested in the role of the mother tongue in second language production as well as language acquisition as a part of cultural integration.

Maija S. Peltola, PhD, is an Associate Professor from the Department of Future Technologies and the head of Phonetics and Learning, Age \& Bilingualism Laboratory at the University of Turku. Her research interests include a wide range of topics related to the perceptional and productional acquisition of non-native speech. 